\title{
DICOTOMIA EXPERIÊNCIA X COMPETÊNCIA: O MERCADO DE TRABALHO PARA OS QUE PROCURAM O PRIMEIRO EMPREGO
}

\author{
DICOTOMY EXPERIENCE X COMPETENCE:THE LABOR MARKET FOR \\ PERSONS WHO SEARCH FOR FIRST EMPLOYMENT
}

\section{DICOTOMÍA EXPERIENCIA X COMPETENCIA: EL MERCADO DE TRABAJO PARA LOS QUE BUSCAN EL PRIMER EMPLEO}

\author{
Renan Gomes de Moura* \\ renangmoura@gmail.com \\ Paloma de Lavor Lopes **, *** \\ palomalavor@gmail.com \\ Marcus Vinícius Barbosa ** \\ Marcus.barbosa1979@gmail.com
}

* Universidade do Grande Rio, Rio de Janeiro, RJ- Brasil
** Centro Universitário Geraldo Di Biase,Volta Redonda, RJ - Brasil
*** Faculdade Sul Fluminense,Volta Redonda, RJ - Brasil

\section{Resumo}

A proposta do presente artigo é levar ao leitor conhecimento sobre o processo seletivo voltado para os que procuram o primeiro emprego traçando um parâmetro com os discursos dos gestores de RH verificando o peso da competência e o da experiência no processo de seleção de pessoal. Para isso o objetivo geral do presente trabalho concentrou-se em investigar o posicionamento do mercado de trabalho para aqueles que buscam o primeiro emprego. Para isso utilizou-se de pesquisas bibliográficas e de pesquisa de campo qualitativa realizada em uma IES particular com alunos do último período do curso de Administração e Recursos Humanos.

Palavras-Chave: Mercado de Trabalho; Recrutamento e Seleção; Competência; Primeiro emprego.

\begin{abstract}
This article aims provide the reader with knowledge about the selective process aimed at those seeking the first job, drawing a parameter with the HR managers' discourses verifying the weight of competence and experience in the personnel selection process. To this end, the general objective of the present study focused on investigating the positioning of the labor market for those seeking the first job. For this we used bibliographic research and qualitative field research carried out in a private university with students from the last period of the Administration and Human Resources course.
\end{abstract}

Keywords: Labor Market; Recruitment and selection; Competence; First job.

\section{Resumen}

La propuesta del presente artículo es llevar al lector conocimiento sobre el proceso selectivo orientado hacia los que buscan el primer empleo trazando un parámetro con los discursos de los gestores de RH verificando el peso de la competencia y el de la experiencia en el proceso de selección de personal. Para ello el objetivo general del presente trabajo se concentró en investigar el posicionamiento del mercado de trabajo para aquellos que buscan el primer empleo. Para ello se utilizó de investigaciones bibliográficas y de investigación de campo cualitativa realizada en una IES particular con alumnos del último período del curso de Administración y Recursos Humanos. Palabras clave: Mercado de Trabajo; Reclutamiento y selección; Competencia; Primer empleo. 


\section{INTRODUÇÃO}

O Mercado de Trabalho é um cenário dinâmico e sofre contínuas mudanças. Observa-se que as transformações no Mercado de Trabalho ocorreram de forma significativa a partir do século XVIII, com a Revolução Industrial, na Inglaterra, quando ocorreram mudanças no meio de produção que consistiu a substituição do trabalho humano pelo trabalho automobilístico, e cada vez mais esse processo vem se transformando e a exigência do mercado vem crescendo junto com essas transformações. "Os aumentos quantitativos de produtividade, naturalmente, são apenas parte panorama. A tecnologia moderna produz, não apenas mais e com maior rapidez; ela produz objetivos que não poderiam ser fabricados de maneira nenhuma com os métodos artesanais do passado" (LANDES, 1994, p. 9-10). Infere-se que, através do que foi exposto, que após a Revolução Industrial o Mercado de Trabalho passou a exigir pessoas qualificadas e experientes, pois os meios de produção abandonaram as características artesanais para adotar características industriais, dando foco na produtividade dos funcionários. Nesse contexto pode-se dizer que foi de extrema importância para as organizações o desenvolvimento do setor de Recursos Humanos, onde o mesmo ficou estritamente ligado a eficácia organizacional e ao comportamento das organizações, pois o mesmo exerce a função de mediador de interesses entre empresa e funcionário a fim de alcançar sucesso organizacional. Ressalta-se que o R.H é fundamental para o sucesso das organizações, tendo em vista que é nele que começa a escolha dos melhores talentos, através do Subsistema de RH de Agregar Pessoas.

O processo de Agregar Pessoas constitui as rotas de ingresso na organização. Representam as portas de entrada que são abertas apenas para candidatos capazes de ajustar suas características pessoais às características predominantes na organização. Há um verdadeiro esquema de filtragem: cada organização codifica as características humanas que são importantes para o alcance dos objetos organizacionais e para a sua cultura interna e passa a escolher aquelas pessoas que possuem elevado grau (CHIAVENATO 1999, pág. 78).

"A experiência ainda exerce um papel importante no desenho de um candidato ideal; toda via, o peso específico dessa característica deixou lugar ao nível de potencial que o candidato traz consigo" (MARRAS 2000, pág. 262). Observa-se que o processo seletivo deve ser baseado em um fator importante baseado na dicotomia experiência x competência, com isso questiona-se: Existem oportunidades para os candidatos que procuram o primeiro emprego? 
A fim de responder esse questionamento o presente trabalho partiu da hipótese que os Recrutadores dão prioridade para profissionais que já possuem experiências profissionais. Sendo assim o objetivo geral do presente trabalho concentrou-se em investigar o posicionamento do mercado de trabalho para aqueles que buscam o primeiro emprego. Já os específicos concentraramse em: a) Compreender a diferença entre Mercado de Trabalho e Mercado de Recursos Humanos; b) Conceituar o processo de Recrutamento e Seleção; c) Analisar o que é competência; d) Investigar as variáveis relacionadas ao primeiro emprego, e) Verificar o posicionamento dos profissionais e dos gestores de RH sobre a dicotomia experiência x competência.

\title{
QUADRO TEÓRICO
}

\section{MERCADO DE TRABALHO E MERCADO DE RECURSOS HUMANOS}

Segundo Chiavenato (1999, pág. 82), “mercado significa o espaço de transações, o contexto de trocas e intercâmbios entre aqueles que oferecem um produto e serviço e aqueles que procuram um produto e serviço." Deste modo pode-se dizer que o Mercado de Trabalho e o Mercado de RH estão interligados, pois um depende do outro, ou seja, o MT oferece produtos e serviços para o Mercado de Recursos Humanos.

\begin{abstract}
As características estruturais e conjuntivas do MT influenciam as práticas de $\mathrm{RH}$ das empresas. Quando o MT está em situação de oferta - quando as oportunidades de trabalho são maiores do que a procura delas - , as organizações se veem diante de um recurso escasso e difícil: as pessoas são insuficientes para preencher as suas posições em aberto. Quando o MT está em situação de procura - quando as oportunidades de trabalho são menores que a procura delas-, as organizações se veem frente a um recurso fácil e abundante: as pessoas que disputam empregos no mercado. (CHIAVENATO 1999, pág. 82 e 83)
\end{abstract}

Observa-se que a Lei da Oferta e Procura de empregos é primordial para compreender como funcionam os mecanismos adotados pelo Mercado de Trabalho. Nos dias atuais a oferta e procura de empregos estão no mesmo patamar, ou seja, há um grande número de empresas ofertando e ao mesmo tempo a um grande número de pessoas procurando (re)colocação no mercado, pois existem pessoas que não possuem qualificação suficientemente para ocuparem os cargos oferecidos pelas organizações. Devido a essa variável encontrada, muitas vezes, na mão-de-obra disponível no Mercado de Trabalho faz-se necessário então a atuação do MRH (Mercado de Recursos Humanos).

Se o mercado de trabalho se refere às oportunidades de emprego e vagas existentes nas empresas, o mercado de recursos humanos (MRH) é o reverso da medalha. Ele se refere ao conjunto de candidatos a emprego. O MRH, ou 
mercado de candidatos, se refere ao contingente de pessoas que estão dispostas a trabalhar ou que estão trabalhando mas dispostas a buscar um outro emprego. (CHIAVENATO, 1999, p.88 - 89)

Nota-se que as pessoas estão se preparando e se qualificando cada vez mais para o mercado de trabalho, as exigências são grandes e junto o aumento da concorrência vem dificultando e valorizando o mercado de recursos humanos. Segundo Chiavenato (1999, pág. 89), “o MRH é constituído de pessoas que oferecem habilidade, conhecimento e destreza", e a partir desta teoria percebe-se que o mercado busca profissionais com qualidade, habilidade, o melhor que o candidato poder oferecer para empresa. Infere-se que a interação entre o MT e o MRH é de extrema importância para aqueles que almejam serem inseridos nas organizações, onde as mesmas utilizam o processo de Recrutamento e Seleção, para encontram pessoas qualificadas e competentes. A seguir será abordada as variáveis que abarcam as questões relacionadas ao Processo de Recrutamento.

\section{RECRUTAMENTO}

O Mercado de Trabalho oferece as vagas e o Mercado de Recursos Humanos oferece os profissionais para ocuparem cargos disponíveis no MT. A partir dessa premissa Chiavenato (1999, pág. 78), faz a seguinte afirmação "O recrutamento funciona como uma ponte entre o Mercado de Trabalho e o Mercado de RH.”.

"O que efetivamente aponta para a necessidade de acionar um serviço de recrutamento e seleção é um dos seguintes acontecimentos: rotatividade, aumento do quadro planejado e aumento de quadro circunstancial." (MARRAS, 2000 p. 66). Através do que foi exposto até o momento é possível inferir que o recrutamento é o primeiro processo para a escolha de funcionários e ele pode ser feito por duas formas, o recrutamento interno e o recrutamento externo. O recrutamento interno é aquele feito dentro da empresa, ou por promoção de cargo, ou por transferência de setor, e o recrutamento externo é aquele onde se busca no mercado de recursos humanos profissionais para estarem suprindo o quadro efetivo de funcionários podendo ser essa busca interna ou externa a organização.

Segundo Marras (2000, p. 71), “o recrutamento interno é aquele que privilegia os próprios recursos da impressa. Isso é, a divulgação das necessidades (vagas em aberto) é informada por meio 
de comunicação o autor ainda salienta que o recrutamento "é o processo de captação de recursos humanos no mercado de trabalho, com o objetivo de suprir uma necessidade de empresa no seu quadro de efetivos". Nota-se que ambos os tipos de recrutamento são favoráveis para a empresa, mas quando se fala de recrutamento externo fica ainda mais evidente em relação ao primeiro emprego, pois sempre visa buscar uma nova opinião, novo conhecimento que não possui dentro da empresa, e quem pode apresentar esse perfil profissional são os que estão começando no mercado profissional, pois estão dispostos a oferecer todo seu potencial para a empresa.

Segundo Milkovich (2000, p. 162, poucas empresas conseguem sobreviver por muito tempo sem contratar sangue novo, funcionários com novas ideias. Para isso algumas empresas então buscando dentro do recrutamento externo, ambientes onde elas possam encontrar pessoas qualificadas e que possuam essas características para serem selecionadas, com essas expectativas das empresas, elas passam a utilizar o recrutamento nas faculdades, pois são locais onde se concentra um elevado número de pessoas dispostas a estarem ingressando no mercado de trabalho, e com isso a empresa pode estar buscando pessoas capacitadas mesmo não possuindo experiência no mercado de trabalho.

A recente escassez de trabalho levou alguns ex-alunos a buscar os serviços de emprego de suas faculdades, mas essa pode não ser uma boa solução. As evidências sugerem que, enquanto esses serviços obtêm os mais altos salários no primeiro emprego, há na realidade uma perda na remuneração daqueles que os utilizam para colocações posteriores. (MILOKOVICH, 2000 p. 178).

Observa-se que o recrutamento externo nas faculdades é de extrema importância quando o foco da empresa passa a ser por pessoas qualificadas, com maior força de vontade para estarem entrando no mercado de trabalho em busca do primeiro emprego, para isso são utilizados métodos no processo de seleção para estarem escolhendo os melhores profissionais, mesmo aqueles que não possuem experiência, mas possuem competência. Para melhor entender o recrutamento a seguir será abordado como são conduzidos os processos seletivos.

\section{SELEÇÃO}

Posterior ao processo de recrutamento advém o processo de seleção, ou seja, escolher dentre os candidatos recrutados, aqueles que se enquadram no perfil da vaga ofertada 
A seleção externa é o processo de coletar e utilizar informações sobre os candidatos recrutados externamente para escolher quais deles receberão proposta de emprego. Frequentemente, é antecedido por uma triagem, que identifica aqueles candidatos obviamente sem qualificação, antes de qualquer informação adicional." (MILOKOVICH, 2000, p. 208)

Infere-se que a seleção de pessoal é de grande importância, pois detém grande parte da responsabilidade do sucesso organizacional, ou seja, os gerentes devem estar atentos na seleção de funcionários, nas suas competências, capacitações, experiências e talentos. O erro na escolha de um funcionário ou sua má colocação dentro da empresa pode culminar em resultados não satisfatórios. Sendo assim, cabe aos gestores de RH conhecer bem o perfil do novo funcionário, pois é essencial para execução das tarefas e do sucesso da empresarial (BOHLANDER, SNELL, SHERMAN 2005, p. 102)

Corroborando com a ideia exposta pelos autores anteriores Stephen (2003 p. 235). Relata que "Esta não e uma tarefa fácil. Felizmente, existe um grande número de pesquisas para ajudar a orientá-lo na triagem e na seleção de candidatos." Observa-se que por não ser uma tarefa fácil as organizações dependem de uma seleção eficaz a fim de preencher o quadro de funcionários com candidatos qualificados e eficazes. (DESSLER 2003. p. 106). A realização e condução de processos seletivos demandam tempo e gastos financeiros, assim torna-se importante possuir um processo de seleção mais assertivo na escolha do futuro membro da organização, pois serão eles que futuramente trarão o retorno financeiro dispendido nesse processo.

Não seria um exagero dizer que a contratação de cada empregado custa para empresa milhões de dólares em salários, benefícios e outras despesas. As atividades de seleção podem custar milhões de dólares quando aplicadas a um grande número de empregados. Entretanto, como esses empregados vão afetar nos resultados da empresa por muitos anos, esse esforço inicial para fazer uma seleção cuidadosa pode trazer extraordinário retorno do investimento. (MILOKOVICH, 2000 p.210)

Nota-se que selecionar candidatos consiste na decisão de contratar e tal decisão pode ser tomada após uma série de procedimentos como: exames médicos/teste de drogas, entrevista com supervisor, seleção preliminar no departamento de RH, investigação da formação, teste de admissão (aptidão, realização), entrevista inicial no departamento de $\mathrm{RH}$, preenchimento do pedido de emprego, pois são nessas etapas que se conhecem os candidatos, se eles possuem aptidão, habilidades, experiência e competência para estarem sendo contratados e alcançarem o sucesso profissional e empresarial (BOHLANDER, SNELL, SHERMAN 2005). 
Etapas como essas são de extrema importância para os recrutadores, pois é a partir da seleção que se obtêm dados sobre os candidatos em potencial que almejam fazer parte do quadro de funcionários. Onde muitas vezes por mais cuidado que se tenha no processo seletivo ainda se corre o risco de obter falhas nas escolhas desses funcionários criando assim um alto nível de rotatividade dentro da empresa e prejudicando seu funcionamento.

Para minimizar o risco de uma má seleção é necessário que os gestores de RH adotem a prática de seleção por competência. De acordo com Milkovich (2000, p.222) "uma pessoa que trabalhou como gerente de uma lanchonete pode ter simplesmente feito sanduiches ou ter gerenciado uma equipe de 10 funcionários". Nota-se que experiência não é sinônimo de competência sendo essa variável de grande importância, pois determinadas vivências profissionais apresentadas no currículo ou expressadas nas entrevistas nem sempre podem ser levadas em considerações, pois muitas vezes esses candidatos podem ter experiência, mas não possuírem competência para ocuparem o cargo ofertado. Através das citações anteriores fica evidente a importância de se realizar o processo de seleção mediado pela competência, pois ela apresenta objetividade e foco que outras ferramentas de seleção não apresentam diminuindo assim a margem de erro na seleção de candidatos. Rabaglio (2012), relata que a seleção por competência é vantajosa por vários motivos, são eles:

Seleção feita com mais foco, mais objetividade e por um processo sistemático. Maior facilidade para prever o desempenho futuro. Maior garantia de uma contratação de sucesso. Boa adequação do profissional à empresa e à atividade a ser desempenhada. Turnover mais baixo e melhora na produtividade. Evita prejuízos com reabertura de processos seletivos e com funcionários ineficientes. Diminui a influência de opiniões, sentimentos ou preconceitos dos selecionadores. $\mathrm{O}$ candidato tende a não mentir, pois deve citar um fato que realmente ocorreu. Fornece dados concretos sobre desempenho do candidato, facilitando o feedback para o candidato. Fortalece a parceria entre área requisitante e área de Seleção. A área de Seleção ganha maior credibilidade junto aos seus clientes requisitantes. A área de Seleção faz um marketing positivo da empresa junto aos candidatos, passando uma imagem de profissionalismo, ética e respeito pelo ser humano.” (ROBAGLIO, 2001)

Através da observação feita por Robaglio (2001) pode-se inferir que a partir desse processo, as organizações terão como escolhas profissionais talentosos, com competência para ocupando a vaga de trabalho ofertada pela empresa, e esse processo poderá ser aplicado principalmente naqueles que estão em busca do primeiro emprego, pois, não necessariamente, pode-se ter experiência, mas durante a seleção por competência esse profissional poderá demonstrar que possui 
talento, habilidade, capacidade e principalmente atitude para preencher a vaga. Para melhor entendimento do processo de seleção por competência será abordado a seguir as questões que abarcam o conceito de competência.

\section{SELEÇÃO POR COMPETÊNCIA}

O termo competência nos últimos anos vem despertando cada vez mais o interesse dos responsáveis pelo gerenciamento de pessoas, pois a dicotomia experiência x competência vem sendo abordada cada vez mais no meio profissional. Porém o que é competência?

Uma definição de competência comumente utilizada entre os profissionais de RH é: conjunto de conhecimento, habilidades, atitudes que afetam a maior parte do desempenho do trabalho; a competência pode ser mensurada, quando comparada com padrões estabelecidos e desenvolvido por meio de treinamento. (ROCHA, 2007, p.38)

De acordo com Chiavenato (2000, p. 166) "competências são aquelas características pessoais essenciais para o desempenho da atividade e que diferenciam o desempenho das pessoas". Completando a ideia exposta anteriormente Fleury e Fleury (2000, p. 21) relatam que competência é "Um saber agir responsável e reconhecido, que implica mobilizar, integrar, transferir conhecimentos, recursos, habilidades que agreguem valor econômico à organização e valor social ao indivíduo.".

Já para Dutra “A competência é compreendida por muitas pessoas e por alguns teóricos da administração como um conjunto de conhecimentos, habilidades e atitudes necessários para desenvolver suas atribuições e responsabilidades". (2001, p. 28). Compreende-se que competência é mais do que possuir uma habilidade para saber fazer, é ser portador de conhecimento para saber e possuidor de atitude para saber ser. Logo, definir a palavra competência é, automaticamente, uma relação consistente com o modelo CHA (Conhecimento, Habilidade e Atitude). Nota-se que nos dias atuais a competência passa a ser um dos requisitos mais valorizados pelas organizações, pois contratar funcionários competentes passa a ser mais vantajoso do que contratar funcionários que possuem experiências isoladas da competência.

Infere-se que o grande diferencial do profissional está na capacidade de transformar o conhecimento tácito em explícito, aplicando de forma harmônica os conhecimentos, as habilidades 
e atitudes dentro de um contexto ideal e propício para a organização. "Ter competências significa ter conhecimentos, habilidades e atitudes compatíveis, com o desempenho de uma atividade e ser capaz de colocar esse potencial em prática sempre que for necessário". (RABAGLIO, 2001, p.2). Corroborado a ideia exposta por Robaglio (2001), Fleury e Fleury (2000, p.19), faz a seguinte observação "uma definição de competência comumente utilizada entre os profissionais de RH é: conjunto de conhecimento, habilidades, atitudes que afetam a maior parte do desempenho do trabalho; a competência pode ser mensurada, quando comparada com padrões estabelecidos e desenvolvido por meio de treinamento." A partir dos conceitos sobre competência, percebe-se que para que as empresas buscar selecionar profissionais sem experiência, com novas atitudes, novas ações, pensamento, características voltadas a profissionais que estão em busca pelo primeiro emprego passa a ser mais vantajoso para uma organização, pois treinam e moldam seus futuros funcionários a perfil da empresa.

\section{PRIMEIRO EMPREGO}

A prática tipicamente humana do trabalho adquiriu um papel central tanto na inserção social de cada indivíduo e na decorrente formação de sua identidade quanto na constituição e na sustentação da sociedade, principalmente nos Estados nacionais modernos fundados na concepção do contrato social. (CASTEL, 1998, p.56).

Ao contrário da experiência internacional, o Brasil vem, nas duas últimas décadas, retrocedendo no uso do tempo livre destinado ao jovem. Guardadas as devidas proporções, o país tem repetido a experiência das primeiras décadas do século passado, quando era maior a presença do jovem no mercado de trabalho. (POCHMANN, 2007, p.35)

Infere-se, através do que foi exposto, que o trabalho está ligado ao desenvolvimento humano, onde ele pode transformar a natureza e a si próprio, mas o trabalho tem se associado principalmente à sobrevivência das pessoas, deixando o desenvolvimento humano. Marcadamente o primeiro emprego do jovem é precário. Ter o primeiro emprego é o sonho de muitos jovens. No entanto, o mercado de trabalho tornou-se mais exigente na escolha dos candidatos, sejam eles profissionais especialistas e maduros ou jovens inexperientes em busca de seu primeiro emprego.

O primeiro emprego representa um momento decisivo para a trajetória futura do jovem no mercado de trabalho. Quanto melhor forem as suas condições de acesso 
ao primeiro emprego, proporcionalmente mais favorável deverá ser a sua evolução profissional. O ingresso precário e antecipado do jovem no mundo do trabalho pode marcas desfavoravelmente o seu desempenho numa possível trajetória profissional (POCHMANN, 2007, p.13).

O primeiro emprego é a porta de abertura de transformação da vida profissional de qualquer indivíduo porém a inserção o Mercado de Trabalho não é tão fácil, quando refere-se ao primeiro emprego (CORRAL, 2010). De acordo com Gonçalves e Monte (2008), dentre as diversas razões encontradas para explicar o maior o desemprego entre os jovens, pode-se destacar: i) o baixo dinamismo econômico, que intensifica o fenômeno do desemprego entre os jovens, ii) a dificuldade de inserção ocupacional, devido à baixa qualidade de ensino, iii) a falta de experiência e/ou habilidades exigidas pelas empresas na hora da contração. Os autores mostraram que os trabalhadores que buscam o primeiro emprego encontram maiores dificuldades para se inserir no mercado de trabalho, devido à falta de experiência. Pensando nessa dificuldade houve a criação de diversas políticas públicas que visam a inserção do Mercado de RH no Mercado de Trabalho como a Lei 10.748/2003 do Programa Nacional de Estímulo ao Primeiro Emprego para Jovens (PNPE), cujo objetivo é inserir e preparar jovens entre os 16 e 24 anos para ingressarem no Mercado de Trabalho.

\footnotetext{
"Art. 1ํㅜㄹ Fica instituído o Programa Nacional de Estímulo ao Primeiro Emprego para os Jovens - PNPE, vinculado a ações dirigidas à promoção da inserção de jovens no mercado de trabalho e sua escolarização, ao fortalecimento da participação da sociedade no processo de formulação de políticas e ações de geração de trabalho e renda, objetivando, especialmente, promover: I - a criação de postos de trabalho para jovens ou prepará-los para o mercado de trabalho e ocupações alternativas, geradoras de renda; e II - a qualificação do jovem para o mercado de trabalho e inclusão social." (BRASIL, 2003)
}

Através do que foi exposto infere-se que o PNE visa a capacitação profissional de desempregados incide em programas transversais aos níveis escolares. O núcleo central desta política é a "formação-qualificação profissional" e tem-se assistido à expansão de formas de combate à desqualificação social.

\section{METODOLOGIA}

O presente projeto de pesquisa propõe uma fundamentação teórica em livros, revistas e periódicos específicos da área de Recursos Humanos e Ciências Sociais. A pesquisa se baseou em 
dois pilares: para revisão de literatura foi feita pesquisa bibliográfica, e para atingir os objetivos propostos foi realizada análise de conteúdo dos resultados obtidos na pesquisa de campo. No que se refere à pesquisa bibliográfica Martins (2011, p. 28), relata que "trata-se, portanto, de um estudo para conhecer as contribuições científicas sobre o tema, tendo como objetivo recolher selecionar, analisar e interpretar as contribuições teóricas existentes sobre o fenômeno pesquisado".

No que se refere a escolha da metodologia utilizada na pesquisa de campo deve-se ao fato de que a mesma busca explicar o porquê dos fatos, exprimindo o que convém ser feito, mas não quantificam os valores e nem se submetem à prova de fatos, pois os dados analisados não são passiveis de serem espremidos de uma forma quantitative, pois "a pesquisa qualitativa não se preocupa com representatividade numérica, mas sim com o aprofundamento da compreensão de um grupo social, de uma organização etc.”(GOLDENBERG, p. 43, 1999).

A seleção de sujeitos foi definida por julgamento, ou seja, os elementos considerados representativos de acordo com os objetivos da pesquisa foram incluídos nela. Malhotra (2011) afirma que esta é uma forma de amostragem por conveniência, segundo a qual os elementos são escolhidos deliberadamente com base no julgamento do pesquisador. Na pesquisa de campo foram entrevistados cem (100) alunos dos últimos períodos dos cursos de Administração e Recursos Humanos de uma IES que estão em busca do primeiro emprego. A pesquisa caracterizou-se pela aplicação de questionários com seis (6) perguntas fechadas e abertas, a fim de tornar uma pesquisa imparcial foram entrevistados dois gestores regionais da área de Recursos Humanos com a aplicação de questionário com seis (6) perguntas abertas.

Análise de Conteúdo, segundo Bardin (1979). É um método que consiste em descobrir os núcleos de sentido, cuja frequência de aparição podem significar algo para o objetivo analítico da pesquisa/objeto de pesquisa. Os passos que compõem a Análise de Conteúdo (Bardin, 1979) são: Pré-análise; Exploração do material; Inferência e Compreensão.

\section{APRESENTAÇÃO E ANÁLISE DOS RESULTADOS}

Apresenta-se a seguir, os resultados da pesquisa de campo. Primeiro serão abordados os resultados da pesquisa realizada com os alunos e posterior serão apresentados os resultados das entrevistas realizadas com os gestores de Recursos Humanos. 
GRÁFICO 1: Sexo dos entrevistados

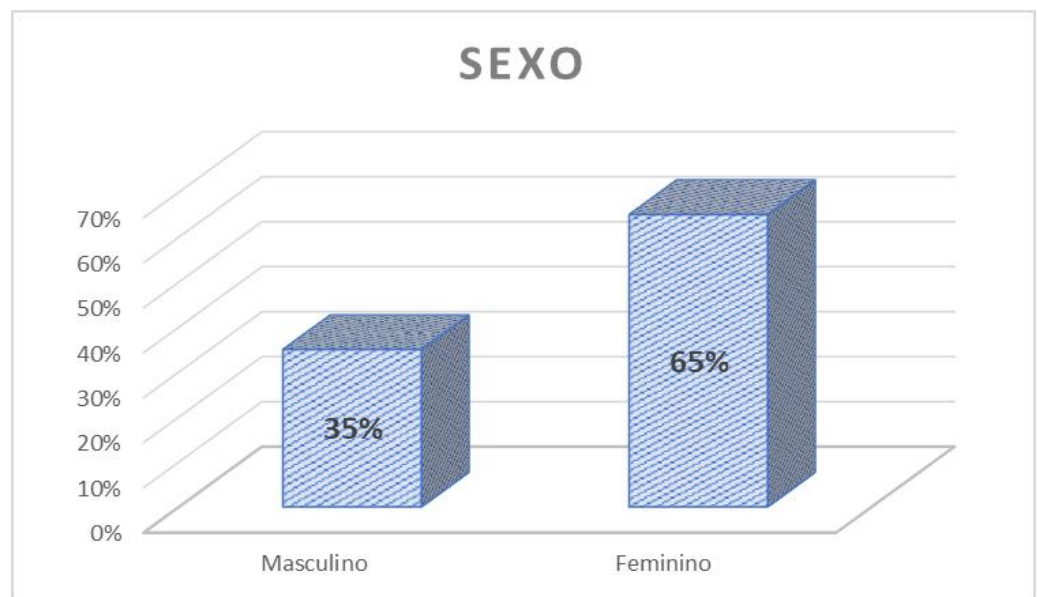

Fonte: Dados coletados na pesquisa de campo (2014)

Através do gráfico 1 percebe-se que $65 \%$ dos entrevistados que procuram o primeiro emprego são do sexo feminino e $35 \%$ do sexo masculino. Quando averiguada a idade obteve-se o seguinte resultado

GRÁFICO 2: Resultados dos processos seletivos

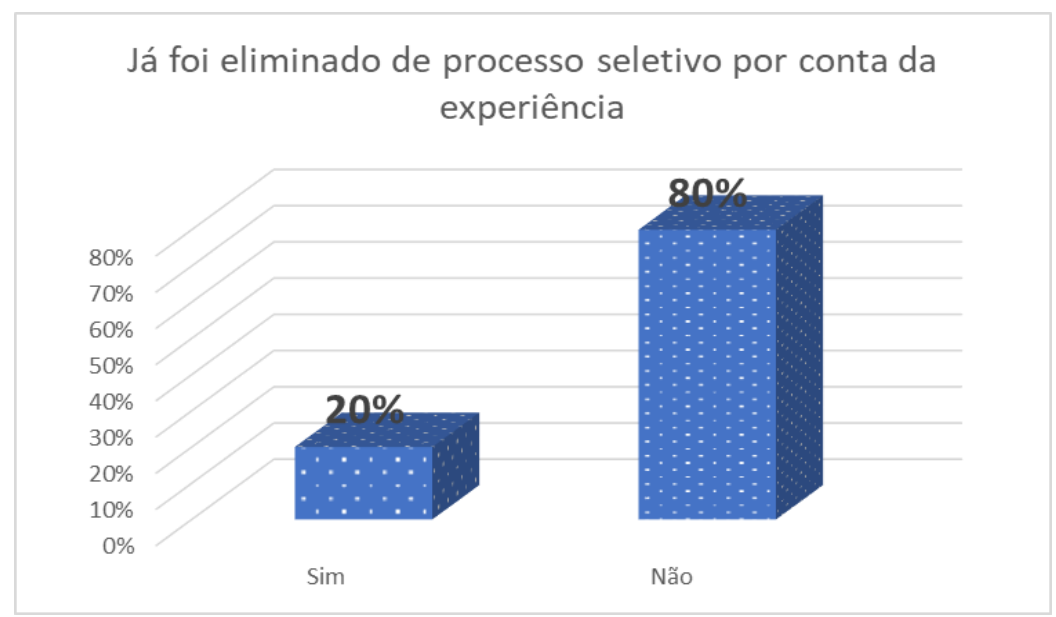

Fonte: Dados coletados na pesquisa de campo (2014)

De acordo com o gráfico 3, $80 \%$ dos entrevistados nunca foram eliminados no processo seletivo por falta de experiência e $20 \%$ já foram eliminados por esse requisito. 


\section{ENTREVISTAS}

\section{Tema: "desclassificação por falta de experiência profissional"}

Cruzando-se os dados da Gráfico 3 com a fala de alguns entrevistados pode-se notar que ainda encontrou dificuldade para inserir-se no mercado de trabalho pelo fato de não possuir experiência profissional: "A empresa disse que como não tinha experiência poderia não ter capacidade de aprender com rapidez" (Entrevistado 1). Por outro lado um dos entrevistados que nunca foi desclassificado em um processo seletivo por não ter experiência, justificou-se da seguinte forma: "As empresas que participei de processo seletivo davam oportunidades para jovens sem experiência, acho que devido ao fato delas oferecerem treinamento próprio para todos os funcionários." (Entrevistado 2)

Baseado nessas justificativas verificou-se com um gestor de RH se a experiência seria ou não um fator eliminatório em um processo seletivo, a partir da pergunta obteve-se como resposta:

"Não, ai depende muito da cultura da empresa, tem empresa que são mais exigentes na questão dos requisitos experiência e hoje estamos em um patamar bem mais avançado na questão do processo seletivo, então a gente vê que as pessoas que vem sem experiência, elas vem sem vícios de outras empresas ai a gente pode estar moldando as pessoas de acordo com essa cultura, então às vezes para gente que recruta, a gente tem um percentual mais positivo quando a gente recruta pessoas e seleciona sem experiência do que com experiência." (Gestor de Recursos Humanos 1)

Perceber-se que algumas organizações aceitam contratar funcionários sem experiência para moldarem conforme o parâmetro da empresa através de treinamento. Outras já buscam pessoas que possuem experiência profissional para ocuparem determinados cargos. Nota-se que o processo seletivo segue sua forma de condução baseada nos princípios que a organização acredita e segue.

\section{GRÁFICO 3: Conhecimento do conceito de competência}




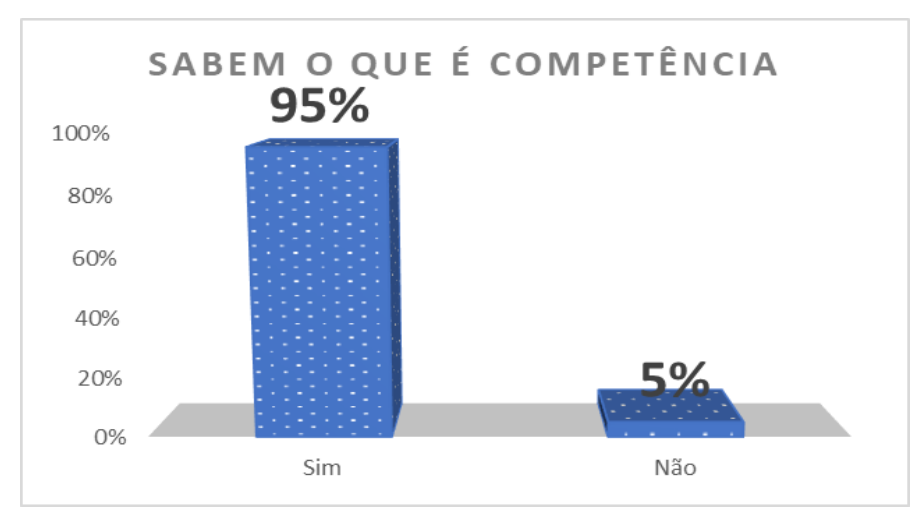

Fonte: Dados coletados na pesquisa de campo (2014)

Como se pode perceber no gráfico 4, $95 \%$ dos entrevistados sabem o que é competência e somente $5 \%$ não souberam definir o conceito de competência.

\section{ENTREVISTAS}

\section{Tema: "Conceito de competência"}

Dentre as respostas dadas pelos entrevistados selecionaram-se duas sobre o que seria competência: "Um diferencial que o indivíduo possui, relacionado ao seu conhecimento $e$ habilidade" (Entrevistado 3). Outra resposta obtida pelos entrevistados foi: "Competência é você ter aptidão e conhecimento para exercer o cargo de interesse”. (Entrevistado 4). Através das respostas dadas pelos entrevistados (universitários) percebe-se que os mesmos não possuem total domínio do que seria competência, porém sabem que está ligado a habilidade e a prática, ou seja, ao fazer de forma eficaz. Quando o gestor foi questionado sobre o conceito de competência obteve-se a seguinte resposta:

\footnotetext{
"Competências são aptidões que a pessoa tem ou desenvolvem de acordo com o tempo, a gente pode estar desenvolvendo várias competências em uma pessoa, por exemplo, na primeira questão você pode ter uma pessoa que não tem experiência você pode estar treinando para que ela desenvolva várias competências que ela tem condição para aplicar na prática, ai depende algumas já têm ai é só você aprimorar de acordo com a empresa outras você pode estar desenvolvendo na pessoa." (Gestor 2)
} 
As falas dos gestores juntamente com a dos universitários mostram que competência é um conjunto de aptidão, habilidade e conhecimento, onde a pessoa pode possuir ou então a empresa pode treinar para desenvolver no indivíduo para que ela adquira conhecimento, habilidade e atitude para executar uma tarefa.

GRÁFICO 5: Competência e experiência

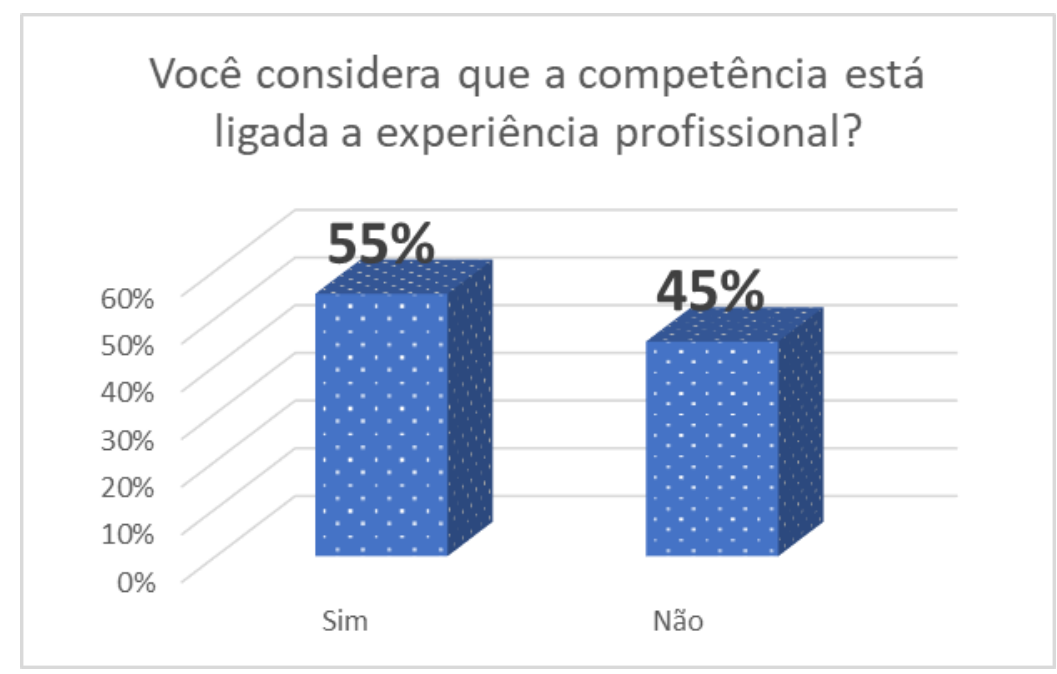

Fonte: Dados coletados na pesquisa de campo (2014)

Percebe-se no gráfico 5 , que $55 \%$ dos entrevistados consideram que a competência e a experiência estão interligadas e $45 \%$ dos entrevistados não consideram que ambas estão interligadas, porem nas justificativas alguns entrevistados entraram com contradições.

\section{ENTREVISTAS}

\section{Tema: "Competência e histórico profissional"}

Dentre as respostas obtidas dos universitários, sobre a relação entre competência e experiência uma que ganhou visibilidade foi: 
Costumo dizer que competência não está naquela universidade específica, muito menos nas pessoas que estão de cabelos brancos, mas sim naquele que tem compromisso, primeiro consigo mesmo, depois com seus clientes tomadores dos seus serviços. Porque nessa vida, a competência está relacionada com persistência, responsabilidade, zelo, firmeza, qualidade, dignidade e honra, porque somente alguém com tais qualidades pode ser competente. Por fim, também é verdade que determinada pessoa com cabelos brancos que durante sua vida toda tratou sua profissão com honradez, tanto tem experiência como competência, contratá-lo será como ter a própria excelência ao seu inteiro dispor. (Entrevistado 5)

Através da resposta do universitário, é possível compreender que nem sempre a competência está atrelada a vivencia profissional, mas sim a sua trajetória para o desenvolvimento de habilidades, conhecimento e sua atitude.

"A experiência é um fator muito relevante na contratação de alguns profissionais, porém, não podemos confundir experiência com competência. É necessária uma avaliação prática e uma entrevista com o profissional para que o responsável possa avaliar até que ponto sua experiência vai pesar na sua contratação. Muitas vezes, nos deparamos com candidatos recém-formados que ainda não possuem uma bagagem significativa, no entanto, quando colocados em ação ou na frente de um grupo se revelam grandes promessas como funcionários" (Gestor 2)

Através do discurso do Gestor 2 nota-se que a preocupação é selecionar o candidato levando em conta sua formação, experiência e especialização na tentativa de aliar conhecimento e experiência. Entretanto, quando um profissional é escolhido para uma vaga através de seu currículo, não se deve fixar primeiramente nas experiências anteriores, mas sim avaliar a sua prática.

GRÁFICO 6: Processo seletivo por competência x experiência

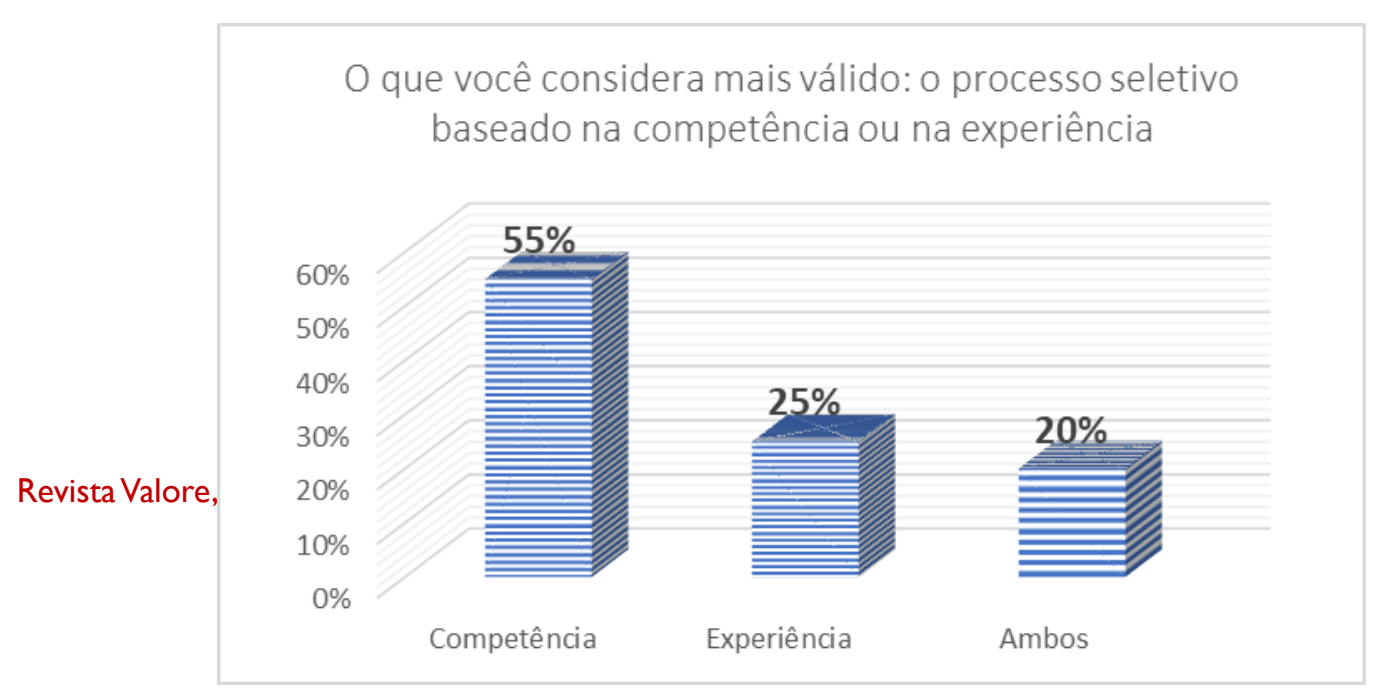


Fonte: Dados coletados na pesquisa de campo (2014)

Através da pesquisa realizada percebe-se que 55\% dos entrevistados consideram mais válido o Recrutamento e Seleção baseado na competência, $25 \%$ consideram o R\&S que valorizam e e realizam suas escolhas a partir das experiências profissionais do candidado e $20 \%$ relatam que o processo mais eficaz para captação de novos colaboradores é o que abordam a competência e a experiência.

\section{ENTREVISTAS}

\section{Tema: "O Processo de agregar pessoas: Competência x Experiência"}

Nessa tema buscou-se verificar o que é mais importante no processo seletivo. Um dos sujeitos relataram que:

"Creio que o processo seletivo baseado na competência seja mais eficiente, pois verifica a existência da habilidade desejada pelos gestores, dando assim, chances para aqueles que desenvolveram habilidades, conhecimento e atitudes a fim de conseguir um lugar no Mercado de trabalho" ( Entrevistado 6)

"Creio que as organizações hoje procuram, profissionais que já tenham vivência profissional, sendo assim o processo seletivo por experiência é mais eficaz." (Entrevistado 7)

O entrevistado 8 fez a seguinte observação:

"Para mim, os dois processos são importantes, pois creio que cada um tem suas particularidades, e devem ser aplicados de acordo com o cargo ofertado, por exemplo, não se pode contratar um diretor organizacional sem esse nunca ter tido uma larga experiência no mercado de Trabalho, porem essa seleção deve ser atrelada a competência do mesmo." (Entrevistado 8) 
Nesse contexto o gestor 1 utilizou o seguinte discurso:

"Em função das rápidas mudanças pelas quais vem sofrendo o mercado de trabalho, o formato de recrutamento no deve ser mais qualitativo, passando a exigir cada vez mais habilidades do profissional. Criatividade, liderança, conteúdo, conhecimento, posicionamento e muitas outras características serão cada vez mais importantes no processo." (Gestor 1)

Em contra partida o Gestor 2 fez a seguinte observação:

"Todos os dois processos são válidos, porem cada empresa possui sua cultura, que vem mudando ao longo do tempo, porém muitas ainda analisam o currículo dos candidatos dando ênfase nas experiências profissionais dos candidatos em potencial, o que acaba por excluir do processo seletivo aqueles que procuram o primeiro emprego. Ressalta-se ainda que muitas organizações não querem ter gastos com treinamentos, sendo esse outro fator que corrobora com o processo seletivo baseado na experiência" (Gestor 2)

Através dos discursos dos alunos e Gestores percebe-se que o processo seletivo deve ser realizado de acordo com a cultura de cada organização. Nota-se também que tanto o processo seletivo por competência, quanto o por experiência são utilizados pelas organizações e cada um possui sua aplicabilidade de acordo com a vaga ofertada.

\section{CONSIDERAÇÕES FINAIS}

As empresas quando iniciam um processo seletivo estão mandando uma mensagem clara aos futuros funcionários de quais são as necessidades da empresa e os requisitos para a contratação. Em muitos casos os candidatos a uma vaga de emprego não conseguem preencher os requisitos e acabam por não conseguir o emprego. Este sistema de gestão prejudica os candidatos recémformados que não possuem experiências suficientes em face das oportunidades que aparecem.

Ressalta-se ainda que o primeiro emprego é decisivo para a trajetória profissional do jovem, principalmente quando o mercado reproduz a desigualdade da dicotomia experiência $\mathrm{x}$ competência, ou seja, estabelecendo os melhores postos de trabalho aos mais experientes. Através da presente pesquisa foi possível retratar a realidade dos jovens brasileiros sendo assim aponta-se como alternativa uma reformulação das políticas públicas de primeiro emprego para que possam 
estar associadas à manutenção do jovem no sistema educacional e que lhe proporcionem vivência profissional, e não apenas estimulá-lo precocemente sair para o Mercado de Trabalho.

A hipótese estabelecida no presente trabalho foi confirmada parcialmente, pois de acordo com discursos dos gestores de Recursos Humanos e dos jovens que procuram o primeiro emprego, o Mercado de Trabalho segue as normas das organizações que disponibilizam as vagas, ou seja, algumas empresas ignoram a vivência profissional no processo seletivo enquanto outras a valorizam. Todos os objetivos propostos no presente artigo foram alcançados, e ressalta-se que esse estudo não se limita ao tema proposto, sendo alvo de futuras pesquisas através de óticas diferentes como a relação gênero e primeiro emprego, qualificação profissional e políticas públicas, entre outros.

\section{Referências}

BARDIN, L. Análise de Conteúdo. Lisboa: Edições 70, 1979.

BOHLANDER, George W. et.al. Administração de Recursos Humanos. São Paulo: Pioneira Thomson Learning, 2005.

BRASIL, Ministério do Trabalho e Emprego - lei 10.748/2003 - PNPE - Programa Nacional de Estímulo ao Primeiro Emprego para Jovens - Luiz Inácio Lula da Silva. Disponível < https://www.planalto.gov.br/ccivil_03/Leis/2003/L10. 748.htm > Acessado em 26/12/2014

CASTEL, Robert. As metamorfoses da questão salarial: uma crônica do salário. Rio de Janeiro: Vozes, 1998.

CHIAVEnato, Idalberto. Gestão de Pessoas: o novo papel dos Recursos Humanos nas organizações. Rio de Janeiro: Elsevier, 1999.
CHIAVENATO, Idalberto. Recursos Humanos. São Paulo: Atlas, 2000.

CORRAL, Janaína Azevedo. Como conquistar seu emprego. São Paulo, Universo dos Livros, 2010.

DESSLER, Gary. Administração de Recursos Humanos. São Paulo: Prentice Hall, 2003.

FLEURY, M.; FLEURY, A. Estratégias Empresariais e Formação de Competências. São Paulo, Atlas, 2000

GOLDENBERG, M. A arte de pesquisar: como fazer pesquisa qualitativa em Ciências Sociais. Rio de Janeiro: Editora Record, 1999

GONÇALVES, M. F; MONTE, P. A (2008). Admissão por primeiro emprego e reemprego no mercado formal do Nordeste: Um estudo 
mesorregional. In VI Encontro Nacional de Estudos

Populacionais, Caxambu. Disponível em http://www.abep.nepo.unicamp.br/encontro2008/docs PDF/ABEP2008 1313. Acesso em 20/12/2014.

GOULART, Iris Barbosa. Temas de Psicologia e Administração. São Paulo: Casa do Psicólogo, 2006.

LANDES, D.L. Prometeu desacorrentado: transformação tecnológica desenvolvimento industrial na Europa ocidental, dês 1750 até hoje a nossa época. Rio de Janeiro: Nova Fronteira, 1994.

MALHOTRA, N. Pesquisa de marketing: foco na decisão. São Paulo: Pearson, 2011.

MARRAS, Jean Pierre. Administração de Recursos Humanos: do operacional ao estratégico. São Paulo: Futura, 2000.

MARTINS, Gilberto de Andrade. Manual para elaboração de monografias e dissertações. São Paulo: Atlas, 2011.

MILKOVICH, George T. Administração de Recursos Humanos. São Paulo: Atlas, 2000.

POCHMANN, Márcio. Caminhos tortuosos na busca por emprego entre os jovens pobres brasileiros. Brasil, 2007.

ROBBINS, Stephen Paul. Administração: mudanças e perspectivas. São Paulo: Saraiva 2003.

ROCHA, Sandra Regina da; et, al. Dimensões funcionais da gestão de pessoas. Rio de Janeiro: Editora FGV, 2007.

RABAGLIO, Maria Odete. Seleção por competências. São Paulo: Educator, 2001 
Recebido em: 25/10/2017

Aceito em: 16/11/2017

Endereço para correspondência:

Nome: Renan Gomes de Moura

cC) (†)

Email: renangmoura@gmail.com

Esta obra está licenciada com uma Licença Creative Commons Atribuição 4.0 Internacional. 